\title{
Peripheral neuropathy after disulfiram administration
}

\author{
CHRISTOPHER GARDNER-THORPE ${ }^{1}$ AND SIDNEY BENJAMIN
}

From the Wessex Neurological Centre, Southampton, and The Royal Bethlem and Maudsley Hospitals, London

SUMMARY Peripheral neuropathy and optic neuritis occurring in alcoholics are sometimes due to the toxic effects of disulfiram rather than to alcohol. Unless this is considered in the management of such patients it is likely that administration of the drug will be continued. In the past there have been reports of 16 cases of peripheral neuropathy and six cases of optic neuritis, possibly caused in this way; these reports are reviewed and a further six cases are described. The effects of disulfiram on the nervous system are briefly discussed.

Peripheral neuropathy is a well-recognized accompaniment of excess alcohol intake, although the cause is not fully understood (Brain and Walton, 1969). Less well known is the association of peripheral neuropathy with disulfiram (tetra-ethylthiuram disulphide, Antabuse, Aversan) administration. We report a further six cases: cases 1 and 2 were seen personally and details of cases $3,4,5$, and 6 were obtained from physicians in other hospitals who were contacted through the Committee on the Safety of Drugs. Cases 5 and 6 are included in an appendix since fewer details were available.

\section{CASE 1}

J.R., a 40 year old male timber preserver, was admitted to the Wessex Neurological Centre, Southampton (case no. 7488) under the care of Dr. L. S. Illis in January 1969. The patient admitted to drinking a maximum of two bottles of whisky daily from the age of 25 to 36 ; at the end of this time, in 1965 , Antabuse $250 \mathrm{mg}$ daily was prescribed. In August 1968, at the age of 39, he noticed the gradual onset of a cold, numb, painful, swollen sensation below the ankles and movements of the feet became weak and caused him to stumble. These symptoms became more pronounced for four months and then started to regress during the month before admission. He emphatically and repeatedly denied taking any alcohol during the whole of this time.

Symptomatic inquiry was otherwise entirely negative, there being in particular no symptoms referable to the upper limbs, no contact with heavy metals, and the only other drug taken was demethylchlortetracycline (Ledermycin) for bronchitis. There was no family history of diabetes mellitus or of neurological disease.

Examination revealed slight weakness of all muscle groups in the lower limbs, most marked in the toe extensors and flexors, and coordination was slightly ${ }^{1}$ Present and reprint address: Research Fellow, Department of Neurology, The General Infirmary, Leeds 1. impaired in all limbs. There was no wasting or fasciculation and the ankle jerks were absent, but all other tendon reflexes were elicited. The plantar responses were flexor. Vibration sense was lost below the knees and position of the toes was poorly appreciated. Pin prick, touch, and temperature sensation were reduced in all toes, fingers, and both thumbs. The calf muscles were not abnormally tender. A clinical diagnosis was made of sensorimotor peripheral neuropathy associated with Antabuse therapy.

Motor nerve conduction studies (Dr. J. R. Preston) revealed a conduction velocity of $36 \mathrm{~m} / \mathrm{sec}$ in the right lateral popliteal nerve, $36 \mathrm{~m} / \mathrm{sec}$ in the left lateral popliteal nerve, and $60 \mathrm{~m} / \mathrm{sec}$ in both right median and right ulnar nerves.

The urine contained neither albumin nor sugar and radiograph of the chest was normal. Haemoglobin was $15.5 \mathrm{~g} / 100 \mathrm{ml}$, , white blood cell count $7,300 / \mathrm{cu}$. $\mathrm{mm}$, ESR $3 \mathrm{~mm}$ in 1st hour, blood film normal, blood urea $37 \mathrm{mg} / 100 \mathrm{ml}$., serum sodium $142 \mathrm{~m}$-equiv/l., potassium 4.2 m-equiv/l., chloride 105 m-equiv/l., bicarbonate 24 m-equiv/l., albumin $3.8 \mathrm{~g} / 100 \mathrm{ml}$., globulin $2.6 \mathrm{~g} / 100 \mathrm{ml}$., electrophoresis normal, SGOT 28 units, alkaline phosphatase 9 King Armstrong units, bilirubin $0.9 \mathrm{mg} / 100 \mathrm{ml}$., zinc turbidity 1 unit, thymol turbidity 1 unit, calcium $9.0 \mathrm{mg} / 100 \mathrm{ml}$., phosphate $2.5 \mathrm{mg} / 100 \mathrm{ml}$., fasting serum cholesterol $265 \mathrm{mg} / 100 \mathrm{ml}$., protein bound iodine 6.0 $\mu \mathrm{g} / 100 \mathrm{ml}$. and $\mathrm{WR}$ negative. There was no porphyrinuria and no malignant cells were found in the sputum. The cerebrospinal fluid contained 1 lymphocyte/cu.mm, protein $55 \mathrm{mg} / 100 \mathrm{ml}$., globulin no excess, and WR negative. Glucose tolerance test, with $50 \mathrm{~g}$ glucose, by mouth, revealed levels (in $\mathrm{mg} / 100 \mathrm{ml}$.) of 86 (fasting at 0 minutes); 120 (at 30 minutes); 130 (at 60 minutes); 98 (at 90 minutes); 80 (at 120 minutes); 56 (at 150 minutes); 62 (at 190 minutes); pyruvate levels (in $\mathrm{mg} /$ $100 \mathrm{ml}$.) were 0.52 (at 0 minutes); 0.91 (at 60 minutes); and 0.93 (at 90 minutes).

The Antabuse was stopped in January 1969 and no change was noted in symptoms or signs when he was seen in April 1969.

During the duration of his treatment, this patient 
appeared well-fed and no variations from a normal common diet were known.

CASE 2

Mrs. B.K., a female artist of high intelligence, with no family history of alcoholism, had a tendency to depressive mood swings and difficulties in relating to other people. Her first marriage, at the age of 23 , ended within a few months when her husband was killed on active service. She remarried at the age of 40 , and this marriage was associated with many difficulties.

She began to drink heavily and took excessive doses of barbiturates and amphetamines. After one year she was admitted to hospital for treatment, which included disulfiram; there was temporary improvement. She continued the intermittent abuse of alcohol, barbiturates, and amphetamines, and suffered from withdrawal symptoms including fits, and at other times received treatment with disulfiram. At the age of 49 she was admitted to the Maudsley Hospital (no. 66-7135) under the care of Dr. E. Hare, where she received treatment for two months, which included disulfiram $500 \mathrm{mg}$ daily. After discharge she remained abstinent for about four months, but subsequently she avoided disulfiram and relapsed, with a further admission to hospital some five months later. On this occasion she received no drugs except diazepam and was discharged after three months with arrangements for psychotherapy.

After discharge from hospital she had several short drinking bouts and after three weeks she was started on disulfiram $1.0 \mathrm{~g}$ daily, which was taken under supervision. In the ensuing three weeks she remained abstinent but took occasional diazepam and barbiturates in addition to disulfiram. During this period she developed a confusional state, characterized by a diminished level of consciousness and disorientation, which necessitated readmission to hospital. At the time of admission no barbiturate could be detected in the blood nor amphetamine in the urine. In hospital the confusional state remitted within four days. Two weeks after admission the patient complained of a burning sensation in both lower limbs. On examination she showed signs of a peripheral neuropathy in both lower limbs which had not been present at the time of admission, with impaired power, absent ankle jerks, a patchy reduction in sensation, and hyperaesthesia of the soles. Haemoglobin, white cell count, ESR, blood urea, electrolytes, and liver function tests were all normal. The neuropathy improved very slowly but four months later walking was still painful and slow.

\section{CASE 3}

Mrs. R. T., aged 35 years, came under the care of Dr. L. J. Clein and Dr. J. Foley at Long Grove Hospital in 1966, whence she was referred to Dr. C. J. Earl at The National Hospital (no. A.33576). For 12 weeks she had noted numbness of her hands and feet and for eight weeks this had prevented her from walking. Her gait was at first markedly ataxic and hysteria was considered. For the preceding seven months she had taken disulfiram $1.5 \mathrm{~g}$ daily due to a history of excess alcohol intake, but it was considered very unlikely that she took alcohol con- $\frac{\text { o }}{z}$ currently. There had previously been a number of $\mathbb{D}$ domestic upheavals and the alcohol intake at one time amounted to one bottle of wine daily, although she also on admitted to having drunk whisky and gin. The later and presenting symptoms of the neuropathy consisted of an 0 intense burning sensation in the soles of her feet, which became progressively more pronounced and eventually $\frac{\rho}{5}$ led to weakness which prevented walking. She had similarly noticed weakness in the upper limbs, particularly in holding small objects.

On examination there was a minimal defect of memory $\overrightarrow{\overline{\vec{s}}}$ as suggested by the Babcock sentence. There was minimal $\overrightarrow{0}$ bilateral facial weakness; in the upper limbs wasting of the forearms and small muscles of both hands was seen, $\frac{\bar{c}}{\bar{s}}$. with weakness of all muscles which was most pronounced $\frac{\vec{\sigma}}{\sigma}$ distally. Similar distal weakness and wasting was noted $\square$ in the lower limbs with bilateral foot drop. The tendon reflexes in the upper limbs were preserved but later in the $\overrightarrow{0}$ illness they became sluggish in the lower limbs; the plantar responses were absent. The sensory abnormalities $\overrightarrow{\vec{\omega}}$ consisted of impairment of pin prick sensation below the $\stackrel{\omega}{\sigma}$ lower forearms and of light touch, pin prick, and temperature distal to the lower third of the legs. In the lower limbs joint position sense and vibration sense were also $\omega$ absent distally and the impairment of joint position sense extended initially to the hips. The late involvement of the $\omega$ tendon reflexes and the marked loss of position sen of suggested posterior column dysfunction.

The results of investigations were as follows: $\mathrm{Hb} 13 \frac{\mathrm{Q}}{\mathrm{g}}$ 을 g/100 ml., WBC 8,400 per cu.mm, ESR $5 \mathrm{~mm} / 1$ h $\overrightarrow{\mathrm{O}}$ Plasma sodium 132 m-equiv/l., plasma potassium $3 . \overline{\text {. }} \subseteq$ m-equiv/1. Urea $18 \mathrm{mg} / 100 \mathrm{ml}$. Total protein $6.2 \mathrm{~g} / 100 \mathrm{~m} \Phi$ Electrophoresis normal. Total bilirubin $0.4 \mathrm{mg} / 100 \mathrm{~m}$ 类 $\overrightarrow{0}$ Alkaline phosphatase 99 i.u./l., SGOT 14 i.u./l., SGF实 16 i.u./l., thymol turbidity 1 unit. Oral glucose tolerance test results were (in $\mathrm{mg} / 100 \mathrm{ml}$.): fasting $-66,30 \mathrm{~min}-$ $99,60 \mathrm{~min}-132,90 \mathrm{~min}-150,120 \mathrm{~min}-104,180 \mathrm{~min}-$ S $_{2}$ 80. Pyruvate metabolism test results (in $\mathrm{mg} / 100 \mathrm{ml}$.): fasting $-1 \cdot 3,60 \mathrm{~min}-2 \cdot 5,90 \mathrm{~min}-1 \cdot 5$. Urine contained no porphyrin products. CSF pressure $60 \mathrm{~mm}$ containing $\frac{\not}{\mathrm{D}}$ 2 lymphocytes, per cu.mm. Protein $40 \mathrm{mg} / 100 \mathrm{ml}$. Lange $\cong$ 0000000000 . Sugar $64 \mathrm{mg} / 100 \mathrm{ml}$. WR negative in blood $\overrightarrow{\vec{\sigma}}$ and CSF. Serum $B_{12}-265 \mu \mu \mathrm{g} / \mathrm{ml}$. Serum folate $2.0 \frac{\mathrm{O}}{3}$ $\mathrm{m} \mu \mathrm{g} / \mathrm{ml}$. BSP retention $5 \%$ at $45 \mathrm{~min}$. Skull radiographnormal. Chest radiograph-old primary tuberculous focus. EEG-no abnormal features. ECG-within normal limits.

ELECTROMYOGRAPHY AND NERVE CONDUCTION VELOCITY On 1, 9, and 30 December 1966 (Group Captain C. B. Wynn-Parry). Evidence of denervation was found in the $ᄋ$ right abductor pollicis brevis, right quadriceps, right $₹$ tibialis anterior, left abductor pollicis brevis, and left 을 gastrocnemius muscles. Complete denervation was found in the first dorsal interosseous and the abductor hallucis muscles. The left median nerve sensory action potential (SAP) was absent and the right median nerve SAP was $N$ reduced being $5 \mu \mathrm{V}$ in amplitude and latency $3 \mathrm{msec}$. The right ulnar nerve SAP was less than $3 \mu \mathrm{V}$ and the nerve action potential was absent in the left lateral $N$ popliteal nerve. 
RIGHT SURAL NERVE BIOPSY (Dr. W. G. P. Mair, no. H. 381/66). An increase in endoneurial collagen was seen in each fascicle studied; osmic acid preparations showed a severe reduction in the number of myelinated fibres. An increased number of vessels was seen in the epineurium and also within the nerve fascicles.

She has been followed up on treatment with thiamine and some improvement has been noted but there was little alteration in physical signs, although the tendon reflexes became depressed. She was readmitted in 1968 when the physical signs were less marked and the ankle jerks had disappeared, and contractures had developed in both achilles tendons.

The results of investigations carried out were as follows: $\mathrm{Hb} 9.4 \mathrm{~g} / 100 \mathrm{ml}$. Blood film-red cells showed anisocytosis and hypochromia. Serum iron $45 \mu \mathrm{g} / 100 \mathrm{ml}$. Blood urea $19 \mathrm{mg} / 100 \mathrm{ml}$. EMG (Group Captain C. B. Wynn Parry): there was reduced amplitude of the right median nerve sensory action potential $(6 \mu \mathrm{V})$ and evidence of severe denervation in the left abductor hallucis and right extensor digitorum brevis muscles, with an increased motor latency in the right lateral popliteal nerve ( 26 $\mathrm{msec}$ ). No ascending nerve action potential was found in the right lateral popliteal nerve. These changes are indicative of a mixed peripheral neuropathy with some evidence of recovery of innervation of the left abductor hallucis muscle.

She was last seen in July 1968, since when she has failed to keep her out-patient appointments.

\section{CASE 4}

J.W., was a 46 year old housewife when she first came under the care of Dr. M. Kremer in November 1966 (N.H. Q.S. no. A.33530). Apart from a history of migraine, she was well until the age of 43 . She said she then began to drink consistently about half a bottle daily of gin. In May 1966 she started to take Antabuse $500 \mathrm{mg}$ daily. In September 1966-that is, after about four months of Antabuse therapy-she noted that her legs tired easily, she fell over on several occasions without knowing why, and soon she noticed difficulty in walking with weakness of the ankles. This difficulty progressed until November 1966 when she needed a stick. During November 1966 she had noticed for the first time pain in the legs and aching in the soles.

During this period of Antabuse administration she had several attacks of loss of consciousness associated with clonic movements of the limbs, thought to be a manifestation of epilepsy. Some alcohol may have been taken during the period of Antabuse administration.

On examination she had palmar erythema and looked unwell. All other abnormal physical signs were confined to the nervous system. All limbs were hypotonic. There was bilateral foot drop and the ankles were weak. The ankle jerks were unobtainable, all other tendon reflexes reduced and the plantar responses flexor. Sensory testing revealed loss of all modalities below the ankles, but the upper limbs were normal.

The results of investigations were: haemoglobin $13.7 \mathrm{~g} / 100 \mathrm{ml}$., total white cell count 7,000 per $\mathrm{cu} . \mathrm{mm}$, ESR $5 \mathrm{~mm}$ in 1 st hour, urine normal. WR was negative in blood and cerebrospinal fluid (CSF), plasma sodium $138 \mathrm{~m}$-equiv/l., potassium $4.0 \mathrm{~m} /$ equiv/l., serum calcium $10.8 \mathrm{mg} / 100 \mathrm{ml}$., inorganic phosphate $3.6 \mathrm{mg} / 100 \mathrm{ml}$., total protein $6 \cdot 1 \mathrm{~g} / 100 \mathrm{ml}$, electrophoresis normal, total bilirubin $0.2 \mathrm{mg} / 100 \mathrm{ml}$., SGOT 12 i.u./l., alkaline phosphatase 84 i.u./l., thymol turbidity 2 units, serum vitamin $\mathrm{B}_{12} 370 \mu \mu \mathrm{g} / \mathrm{ml}$. CSF was clear and colourless, pressure $100 \mathrm{~mm}$, containing '1 lymphocyte/cu.mm, protein 45 $\mathrm{mg} / 100 \mathrm{ml}$. Lange curve showed no change. Blood alcohol was not detected. Pyruvate metabolism test ( $50 \mathrm{~g}$ glucose at 0 and $30 \mathrm{~min}$ ), fasting pyruvate level was $0.8 \mathrm{mg} / 100 \mathrm{ml}$., $1 \mathrm{hr} 1.4 \mathrm{mg} / 100 \mathrm{ml}$., $2 \mathrm{hr} 1.0 \mathrm{mg} / 100 \mathrm{ml}$. Chest and skull radiographs were normal.

ELECTROMYOGRAPHY (Dr. R. G. Willison). There was total denervation of the extensor digitorum brevis muscle. Stimulation of the anterior tibial and lateral popliteal nerves failed to elicit motor unit responses. Conduction velocity in the sciatic nerve to tibialis anterior muscle was $48 \mathrm{~m} / \mathrm{sec}$; motor and sensory conduction was normal in several nerves of the upper limb.

Left sural nerve biopsy (Dr. W. G. P. Mair, no. H.398/66) showed an increase in endoneurial collagen in each fascicle studied; osmic acid preparations showed a severe reduction in the number of myelinated fibres. An increased number of vessels was seen in the epineurium and also within the nerve fascicles

It was recommended that the Antabuse be discontinued; when she was seen in February 1967, there was minimal evidence of improvement in the neuropathy.

\section{PREVIOUS REPORTS}

PERIPHERAL NEUROPATHY Peripheral neuropathy has been reported in association with disulfiram administration on several previous occasions.

Knutsen (1949) reported the case of a 37 year old man who suffered from anxiety neurosis and took alcohol as a stimulant. For two months he took Aversan, and in the final week of this period he took 40 tablets in a single dose, but no alcohol. He was admitted to hospital in a confused state with hallucinations, nausea and vomiting, urinary retention and acidosis. When his psychiatric state improved after five days, he was found to have bilateral facial weakness and mild weakness of all limbs with alteration of the lower limb reflexes and reduction of skin sensation in the lower limbs; the cerebrospinal fluid was normal. Confusion of uncertain causation recurred within a few days. There was improvement of his peripheral neuropathy at a later date, and this disability was attributed to his large doses of Aversan. The same author reported a case of fatal hepatic failure in a patient taking disulfiram.

Revilliod (1950) mentions two cases of relapse of polyneuritis (and one of death in acute pulmonary oedema) in patients in Swiss hospitals, associated with disulfiram therapy, but the relationship seems in doubt. 
Child, Osinski, Bennett, and Davidoff (1951) in their study of 120 patients treated with Antabuse noted a 'questionable peripheral neuritis in three cases', and imply that side-effects would be uncommon if the drug were not started until at least one week after the last ingestion of alcohol. He also reported demyelination in the brains of rats given toxic doses of the drug.

Charatan (1953) reported the case of a 40 year old man who had drunk heavily for 24 years, at which time his intake rose to two bottles daily of gin. He was treated with tetraethylthiuram disulphide $500 \mathrm{mg}$ daily and after three months of abstinence he noted paraesthesiae and numbness in the lower limbs; he was found to have skin sensory loss over the front of the feet and reduction of the ankle jerks. The drug was stopped and these features started to resolve.

Barry (1953) reported the case of a patient aged 28 who took Antabuse irregularly for four weeks without alcohol. He described painful tinglings in the palms and soles, tender calves, and tiredness. The drug was stopped, vitamin B1 given $(500 \mathrm{mg}$ within seven days) and the symptoms disappeared altogether.

Hayman and Wilkins (1956) report seven cases of peripheral neuropathy associated with disulfiram administration; six cases were thought to be due to chronic intoxication with the drug, since this complication had developed after at least four months' treatment in each of these cases, the longest period being 12 months. The cerebrospinal fluid protein in two of the patients was raised $(68.3$ and $56.3 \mathrm{mg} /$ $100 \mathrm{ml}$.).

The seventh case was of a mild mixed peripheral neuropathy which appeared one day after the first disulfiram-alcohol test, with mild delirium for three hours, and bronchospasm. Recovery occurred in this patient after five days, and six further tests were performed over the coming months without incident.

The neuropathic symptoms disappeared in all patients within some months of onset; in five patients the drug was discontinued; the sixth patient's symptoms persisted as long as the drug was given and subsided when it was stopped; and the seventh patient developed the neuropathy after an alcoholdisulfiram reaction.

Bradley and Hewer (1966) described a patient who took disulfiram $1 \mathrm{~g}$ daily for at least seven months, with chlordiazepoxide, ethchlorvynol, and triclofos, but no alcohol. Over the course of 48 hours he developed a severe mixed peripheral neuropathy; the disulfiram was discontinued and polyvitamin preparations given; there was some progressive improvement eight weeks after the onset.
OPTIC NEURITIS Several cases of optic neuritis $Z$ attributed to disulfiram have been reported, but there was no evidence of this in any of our patients.⿳亠丷厂

Dent (1950) reported the case of a confirmed? alcoholic who took Antabuse daily, but found the symptoms of alcohol deprivation to be so unbearable that he took alcohol concurrently with the drug foro two months; he developed bilateral optic neuritis. with scotomata, but apparently recovered later.

Humblet (1953) reported the case of a 39 year old man who took Antabuse daily for 12 months at thes? end of which time he presented with bilateral centrato scotomata; it was at first uncertain whether this should be attributed to tobacco (he smoked $25 \frac{\bar{c}^{\circ}}{\mathrm{a}}$ cigarettes daily) or to the Antabuse; vision improved $\frac{\mathbb{\Phi}}{2}$ to normal within three months of stopping the druga but his alcohol consumption then rose and the Antabuse was re-started with no ill-effects.

Appelmans (1953) noted that a patient who devel $-\vec{\omega}$ oped optic neuritis while taking Antabuse was alsoo a heavy smoker. Visual acuity started to improve within seven weeks of stopping both Antabuse ando tobacco.

Pommier and Reiss-Byron (1963) and Woillez, $\dot{t}$ Asseman, and Blervacque (1962) reported simifarts cases.

Perdriel and Chevaleraud (1966) report the case of a 37 year old woman who had taken disulfirapin$500 \mathrm{mg}$ daily for 18 months. She then developgd bilateral optic neuritis from which she recovered $\bar{D}$ when the drug was stopped. She continued to smotgect 20 cigarettes daily.

DISCUSSION

To a total of 16 cases of peripheral neuropathy and six cases of optic neuritis associated with disulfiram administration collected from a survey of the literature, we add a further six cases to make a totalö of 28. Many of the case reports, including some of ours, are indefinite and unsupported by good electrophysiological and pathological data. Nevertheless, there are good grounds for believing that disulfiram may induce a symmetrical peripheralo neuropathy, usually of mixed sensory and motoro type, or an optic neuritis in patients who have ceased taking alcohol.

Alcohol is detoxicated in the body tissues by oxidation in three stages (Wortis, 1963): acetalde-윽 hyde is formed in many tissues, particularly the liver; this acetaldehyde is oxidized to acetic acid; and the acetic acid (and possibly some acetaldehyde) is N oxidized to carbon dioxide and water. Disulfiram ${ }^{\mathrm{N}}$ is known to interfere with various enzyme systems 0 including those involved in the oxidation of alcohol. After a test dose of alcohol, administration of di-O 
sulfiram raises the blood acetaldehyde level to about five times that in the patient who is not taking disulfiram (Child et al., 1951). The unpleasant effects that follow alcohol intake (and upon which the value of the drug depends in a patient concurrently taking alcohol) are thought to result from accumulation of metabolites, particularly acetaldehyde.

Although disulfiram has been widely used for more than 20 years, reports of effects on peripheral nerves are few, and this complication is probably uncommon. However, toxic effects on the central nervous system have been reported regularly by many workers, and these include vague symptoms such as drowsiness, headache, vertigo, insomnia, forgetfulness, and disorientation (McNeill, 1951). Toxic confusional states are common, and in one review of 3,722 patients summarized from 20 papers in nine countries, a total of 82 patients $(2 \cdot 2 \%)$ suffered this complication (Schedifka, 1964). Whether these are direct neurotoxic effects of the drug or due to interference with pathways of carbohydrate metabolism remains doubtful. Certainly the report of Child et al. (1951) of demyelination in the brains of rats would support a neurotoxic theory, and clinical experience suggests that these toxic effects are directly related to the administered doses.

Nevertheless, in a discussion of drugs used for the control of alcoholism, Chaftez (1967) mentioned that patients maintained on disulfiram $500 \mathrm{mg}$ daily develop symptoms of polyneuritis, and that, although some workers use only $125 \mathrm{mg}$ daily, in that author's experience $125 \mathrm{mg}$ is an unsatisfactory maintenance dose.

Feldman (1957) is one author who used $125 \mathrm{mg}$ daily and believed sufficient protection was supplied with no cumulative effect and no late complications, even after at least two years' continuous treatment.

The makers of one preparation (personal communication, 1969) state that the maintenance dose of disulfiram should not exceed $200 \mathrm{mg}$ daily (even though each tablet contains $500 \mathrm{mg}$ ), since overdosage tends to produce side-effects. It will be seen from the reported cases that this dose has been exceeded in all cases and generally most workers prescribe 500 to $1,000 \mathrm{mg}$ daily. It is possible that a similar toxic effect contributes to the involvement of peripheral nerves, but usually either the central or the peripheral nervous system is singled out (both were involved in only one of our cases). There is some evidence that other mechanisms play an important part. Some cases have occurred after test doses of alcohol, and in these it may be the accumulation of acetaldehyde and other breakdown products that is responsible for the neuropathy. In particular, acetaldehyde is known to be toxic to animals deficient in thiamine (Handler, 1958), and chronic alcoholics are commonly shown to have abnormal pyruvate tolerance tests, and hence, by implication, a deficiency in thiamine. Thiamine deficiency is known to induce a peripheral neuropathy, and it may be that this is potentiated by acetaldehyde.

In a study of the effects of vitamin deficiency on peripheral neuropathy in alcoholics, Fennelly, Frank, Baker, and Leevy (1964) measured circulating B-complex vitamins in alcoholics with and without peripheral neuropathy and in control subjects. The findings of reduced circulating levels of these vitamins in over $80 \%$ of alcoholic patients with a peripheral neuropathy and $40 \%$ without, together with an improvement in the clinical state when these vitamins were administered, is evidence that alcoholic peripheral neuropathy is at least in part due to hypovitaminosis B. The subject was reviewed by Mawdsley and Mayer (1965).

Morgan (1968) has produced further evidence, albeit controversial (Editorial, 1968, Lancet) that thiamine deficiency may have complicated effects on nervous tissue. Unfortunately, little is known of the nutritional and vitamin status of our patients, but this is clearly of importance in attempting to assess the vulnerability of the nervous system to another toxin.

It has been suggested that enzyme systems in addition to those concerned with the oxidation of acetaldehyde are involved; Jacobsen (1970, personal communication) draws attention to the inhibition by disulfiram of beta-oxidation of dopamine with blocking of formation of noradrenaline from dopamine. While this may play a part in producing mental symptoms, definite proof is lacking, and it seems unlikely that it is the cause of peripheral nerve involvement. Jacobsen (1967) also refers to the earlier suggestion (Merlevede and Casier, 1961) that it is caused by carbon disulphide produced by the elimination of disulfiram, but again there is no proof of this. Physiological studies (Veillefosse and Weizmann, 1957) have shown that disulfiram causes reduction of oxygen consumption, particularly in the brain, and this may reflect changes in the enzyme systems discussed above, or a more direct effect on oxygen uptake by cerebral tissue. Brundin (1964) showed in rabbits that the ethanol-disulfiram reaction induces a respiratory alkalosis with secondary hypokalaemia; probably more complex electrolyte changes also occur.

\section{CONCLUSIONS}

The clinical effects of disulfiram on the central nervous system are well known but the probable association between this drug and peripheral neuropathy has not been widely recognized. If it is 
invariably assumed that this complication is due to the effects of alcohol poisoning, then there is a danger that the drug will not be withdrawn, with further deterioration in the neuropathy. There is clinical evidence that with early withdrawal of the drug there is subsequent remission of the neuropathy in some cases. While the exact means by which this toxic effect is produced remains uncertain, it is likely that the drug has a direct toxic effect on the iissue of the central nervous system and peripheral nerves, and also acts by interference with a variety of enzyme systems, and by allowing accumulation of toxic metabolites.

We are very grateful to Dr. L. S. Illis for his helpful advice, criticism, and encouragement in the preparation of this paper. We are also deeply indebted to Dr. W. H. W. Inman, senior medical officer, Committee on Safety of Drugs for help in contacting the physicians who have cared for these patients and for their permission to publish, and also to those electrophysiologists and pathologists who have kindly supplied the details of investigations; their names are included in the text. Dr. Ilse Stevenson kindly translated the Scandinavian literature. We are most grateful to Miss Diana Hill for much secretarial help.

\section{REFERENCES}

Appelmans, M. (1953). Discussion following paper of Humblet, M. Bull. Soc. belge. Ophtal., 104, 301.

Barry, W. K. (1953). Peripheral neuritis following tetraethylthiuram disulphide treatment. Brit. med. J., 2, 937.

Bradley, W. G., and Hewer, R. L. (1966). Peripheral neuropathy due to disulfiram. Brit. med. J., 2, 449-450.

Brain, W. R., and Walton, J. N. (1969). Diseases of the Nervous System, p. 817. 7th edit. Oxford University Press: London.

Brundin, T. (1964). Alkalosis during the disulfiram-ethanol reaction in unanaesthetized rabbits. Acta pharm. int. (Kbh.), 21, 397-400.

Chaftez, M. E. (1967). Drugs in the treatment of alcoholism. Med. Clin. N. Amer., 51, 1249-1259.

Charatan, F. B. (1953). Peripheral neuritis following tetraethylthiuram disulphide treatment. Brit. med. J., 2, 380.

Child, G. P., Osinski, W., Bennett, R. E., and Davidoff, E. (1951). Therapeutic results and clinical manifestations following the use of tetraethylthiuram disulfide (Antabuse). Amer. J. Psychiat., 107, 774-780.

Dent, J. Y. (1950). Discussion following paper of A. S. Paterson.

Editorial (1968). Hallucinations, alcohol withdrawal, and thiamine deficiency. Lancet, 1, 350.

Feldman, D. S. (1957). Drug therapy of chronic alcoholism. Med. Clin. N. Amer., 41, 381-392.

Fennelly, J., Frank, O., Baker, H., and Leevy, C. M. (1964). Peripheral neuropathy of the alcoholic: aetiological role of aneurin and other B-complex vitamins. Brit. med. J., 2, 1290-1292.

Handler, P. (1958). Metabolism of thiamine. Fed. Proc., 17 (Supp. 2), 31-35.

Hayman, M., and Wilkins, P. A. (1956). Polyneuropathy as a complication of disulfiram therapy of alcoholism. Quart. J. Stud. Alcohol, 17, 601-607.

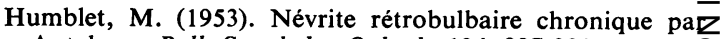
Antabuse. Bull. Soc. belge Ophtal., 104, 297-301.

Jacobsen, E. (1967). Die Verwendung von Disulfiran (Antabus). Med. Welt. 2 (NF), 2230-2234.

Jacobsen, E. (1970). Personal communication.

Knutsen, B. (1949). Komplikasjoner ved antabus-behandling $T$. norske Laegeforen, 69, 436-437.

Mawdsley, C., and Mayer, R. F. (1965). Nerve conduction if alcoholic polyneuropathy. Brain, 88, 335-356.

McNeill, A. J. (1951). 'Antabuse' in the treatment of alcohol ism with a report of 150 cases. Dallas med.J., 37, 75-80.

Merlevede, E., and Casier, H. (1961). Teneur en sulfure dè carbone de l'air expiré chez des personnes normales ov sous l'influence de l'alcool éthylique au cours du traitement par l'Antabuse (disulfiram) et le diéthyldithiocarbamate de Soude. Arch. int. Pharmacodyn., 132, 427-453.

Morgan, H. G. (1968). Acute neuropsychiatric complica tions of chronic alcoholism. Brit. J. Psychiat., 114, 85-92

Paterson, A. S. (1950). Modern techniques for the treatmen of acute and prolonged alcoholism. Brit. J. Addict. ڤ్ 47, No. 2, pp. 3-20.

Perdriel, G., and Chevaleraud, J. (1966). A propos d'ur $\vec{P}$ nouveau cas de névrite optique due au disulfirame. Bull $\overrightarrow{\overrightarrow{.}}$ Soc. Ophtal. Fr., 66, 159-165.

Pommier, and Reiss-Byron (1963). Névrites rétro-bulbaires au disulfirame. Bull. Soc. Ophtal., 63, 254-256.

Revilliod (1950). Discussion following paper of A. S흥 Paterson.

Schedifka, R. (1964). Die Disulfirambehandlung des Alket holismus. $Z$. ärztl. Fortbild., 58, 424-435.

Veillefosse, R., and Weizmann, H. (1957). Travaux récegits sur le traitement de l'alcoolisme par le disulfirame. Reyc Alcool., 4, 142-156.

Woillez, M., Asseman, R., and Blervacque, A. (19\&3).Névrite toxique médicamenteuse au cours de la des? intoxication éthylique. Bull. Soc. Ophtal Fr., 75, 350-387

Wortis, S. B. (1963). In Cecil-Loeb Textbook of Medicine p. 1729. 11th edit. Edited by P. B. Beeson and McDermott. W. B. Saunders: Philadelphia.

\section{APPENDIX}

CASE 5 W.J.B., a 35 year old Jamaican woman, was్ admitted to Warley Hospital (no. 65/1314/136), underD the care of Dr. C. P. B. Brook in May 1964 with a three year history of excessive alcohol intake, the preciseo amount being uncertain. She was thought to be of inadequate personality and depressed. She was given Antabuse $500 \mathrm{mg}$ each night, and about 10 days after? starting this complained of weakness of the legs, with cramps and hyperaesthesia. The drug was discontinued and Parentrovite was substituted, and her symptoms resolved within one month. Artane and chloral were 3 administered concurrently with Antabuse; alcohol intake was thought unlikely but was not, of course, definitely을 excluded.

CASE 6 G.H.B.P., a 41 year old brewer's bottler, drank $\stackrel{\circ}{\supset}$ large quantities of beer but no spirits for many years. Heo became depressed and was admitted to the Mid-Wales Hospital under the care of Dr. G. Diggle in April 1968, $\mathrm{N}$ where his depression responded well to treatment, which included promazine, diazepam, sodium amytal, and으 vitamins. He was discharged in May 1968 taking Anta-c buse $500 \mathrm{mg}$ daily. He presented to his family doctor in 
August 1968 with severe pain in the feet which prevented sleep, and stocking-type sensory loss. His denial of alcohol intake since discharge from hospital was considered reliable. The symptoms were attributed to a peripheral neuropathy without motor involvement, and there was said to be a marked clinical similarity to the neuropathy of Thalidomide. There was no improvement by September 1968, but by October 1969 the pain had disappeared completely, although he still complained of numbness in both feet and both hands.

\section{ADDENDUM}

Since this paper was submitted, Dr. K. W. G. Heathfield has kindly sent us details of another case of peripheral neuropathy associated with disulfiram administration:
CASE 7: K. M. B., a 57 year old physiotherapist, admitted to a daily intake of 1 bottle of gin, brandy or sherry: treatment with disulfiram was instituted, but unfortunately the details of dosage are uncertain. She was referred on account of headache and depression, and was found to have tremor of the hands and absent ankle reflexes; both optic discs were pathologically pale and bilateral central scotomata to red objects, with irregular margins extending to $7^{\circ}$ of the fixation points in all quadrants, suggested bilateral optic nerve involvement. She has not attended for follow-up, but the clinical features at the time of first attendance strongly suggested that the peripheral neuropathy and optic neuritis were associated with disulfiram therapy rather than directly with the excessive alcohol intake. 